\title{
AÇÕES AFIRMATIVAS NA \\ DÉCADA DE 2000 E SUAS \\ CONSEQUÊNCIAS PARA \\ O PERFIL DISCENTE DAS \\ UNIVERSIDADES FEDERAIS
}

\author{
Renato Schwambach Vieira ${ }^{\mathrm{I}}$
}

Adriano Souza Senkevics ${ }^{\mathrm{II}}$

Mary Arends-Kuenning ${ }^{\mathrm{III}}$

http://dx.doi.org/10.24109/9786558010074.ceppe.v3a4

\section{RESUMO}

Na década de 2000, as universidades federais brasileiras passaram a adotar políticas de ação afirmativa nos processos seletivos de seus cursos de graduação. Nesse período, que compreende até a aprovação da Lei de Cotas em 2012, diversas instituições de educação superior definiram políticas de ação afirmativa com diferentes critérios e públicos-alvo. Neste trabalho, descrevemos a associação entre a adoção de ações afirmativas e as mudanças no perfil discente dessas universidades. O perfil dos alunos é mapeado com base nos questionários do Exame Nacional de Desempenho de Estudantes (Enade). O estudo mostra que, nas universidades em que programas de ações afirmativas foram implementados, houve aumento na matrícula de indivíduos pertencentes a grupos explicitamente visados por esses programas, geralmente estudantes do ensino médio público e negros. Demonstramos, ainda, que esse efeito se concentrou em cursos acadêmicos mais competitivos e de maior prestígio. Por fim, encontramos que incrementos na matrícula de estudantes negros aconteceram tão

I Doutor em Economia Aplicada pela Universidade de Illinois e consultor econômico para o Banco Mundial e para a Fundação Instituto de Pesquisas Econômicas (Fipe).

II Doutorando em Educação pela Universidade de São Paulo (USP) e pesquisador do Instituto Nacional de Estudos e Pesquisas Educacionais Anísio Teixeira (Inep).

III Professora no Departamento de Economia Aplicada e diretora do Instituto Lemann de Estudos Brasileiros na Universidade de Illinois. 
somente nas universidades que adotaram políticas com critérios raciais explícitos. Esses resultados indicam, em conjunto, que os primeiros programas de ação afirmativa foram efetivos em aprimorar o acesso ao ensino superior entre suas respectivas populações-alvo, porém, os resultados dos diferentes tipos de programa não foram homogêneos. O entendimento dessas diferenças pode contribuir para o debate sobre o redesenho das políticas de ação afirmativa.

Palavras-chave: ação afirmativa; educação superior; sistema de cotas; relações raciais.

\section{INTRODUÇÃO}

Este artigo visa analisar descritivamente como os primeiros programas de ações afirmativas (AA), instituídos ao longo da década de 2000, alteraram o perfil discente das universidades federais no Brasil. A fim de subsidiar futuras concepções e reformulações de políticas públicas, procuramos somar esforços a pesquisas recentes que avaliam os resultados e impactos das AA sobre a composição socioeconômica das universidades brasileiras, de modo a alimentar o debate público com evidências sobre como tornar as instituições de educação superior (IES) mais inclusivas e representativas do perfil populacional.

Dito isso, este texto se organiza em quatro seções, além da introdução. $\mathrm{Na}$ primeira, contextualizaremos a adoção de políticas de AA no Brasil por meio de um breve panorama dos últimos 20 anos. Em seguida, apresentaremos as bases de dados e a metodologia utilizada, demonstrando os limites e as potencialidades para o estudo em tela. Depois, exploraremos os resultados, os quais, além de uma discussão sobre as alterações gerais no perfil discente, também permitirão uma análise centrada na comparação entre cursos com distintos graus de competitividade e entre programas de AA com e sem critério racial para delimitação dos beneficiários. As considerações finais sintetizam os principais achados, ponderam as limitações do estudo e prospectam novas possibilidades de pesquisa.

\section{AÇÕES AFIRMATIVAS NO CONTEXTO NACIONAL}

Mais do que desigual, o Brasil pode ser considerado uma nação historicamente tolerante à desigualdade. Além de ter sido o último país ocidental a abolir a escravidão, também foi uma das nações latino-americanas que mais tardiamente se ocupou da consolidação de um sistema de educação superior (Neves; Martins, 2016). Até meados da década de 1990, o ensino superior brasileiro apresentou as características de um sistema elitizado, pois era altamente seletivo e destinado a incorporar membros das 
camadas sociais privilegiadas (Gomes; Moraes, 2012). Somente no início dos anos 2000, cerca de 40 anos depois dos Estados Unidos (Holzer; Neumark, 2006), o Brasil passou a adotar políticas de AA, com especial atenção para os programas de reservas de vagas, os quais se consolidaram como o principal mecanismo empregado pelas universidades com o objetivo de ampliar a inclusão na educação superior. Ainda nos dias correntes, as preocupações expressas em tais políticas foram atualizadas nas Estratégias 12.5 e 12.9 do Plano Nacional de Educação (PNE, Lei nº 13.005/2014), cujo escopo é reduzir as desigualdades socioeconômicas e étnico-raciais no acesso e na permanência estudantil em nível superior, por meio da ampliação da participação de grupos historicamente desfavorecidos.

A experiência pioneira com políticas de AA para admissão em universidades brasileiras foi o programa de cotas da Universidade do Estado do Rio de Janeiro (UERJ). Introduzido em 2003, reservou 45\% das vagas da graduação para estudantes do ensino médio público (EMP), negros, indígenas e com deficiência. Em 2004, a Universidade de Brasília (UnB) tornou-se a primeira universidade federal a implementar um programa de AA no processo seletivo de seus ingressantes, tendo estabelecido um sistema de cotas que reservava $20 \%$ das vagas para candidatos negros. No decorrer dos anos, muitas outras instituições públicas criaram suas próprias políticas de AA e, no final daquela década, a maioria das universidades federais já adotara algum tipo de programa de AA em seus processos de admissão.

Em 2012, o governo federal promulgou a Lei $\mathrm{n}^{0} 12.711$ (Lei de Cotas), que resultou em uma expansão sem precedentes na adoção de políticas de AA para admissão em instituições federais pelo País. A Lei de Cotas limitou a heterogeneidade dos programas de AA, pois todas as instituições passaram a ter que cumprir as regras da política nacional, embora fosse dada margem para cotas suplementares, desde que respeitados os patamares mínimos da legislação.

Os efeitos da política nacional de cotas sobre as universidades e os institutos federais têm sido estudados tanto em âmbito local quanto nacional por um leque ainda curto de pesquisas recentes (Carvalhaes; Feres Júnior; Daflon, 2013; Vilela et al., 2017; Karruz, 2018; Mello, 2018; Senkevics; Mello, 2019). Neste texto, as análises limitam-se a explorar o período anterior à promulgação da referida lei, compreendendo desde as primeiras experiências no início dos anos 2000 até a aprovação da legislação federal em 2012. Durante esse intervalo, as universidades federais puderam definir seu próprio desenho de AA, com liberdade para delimitar os critérios de corte e mecanismos de inclusão (Daflon; Feres Júnior; Campos, 2013), assim como a possibilidade de não adotar nenhuma política em particular.

Como a experiência brasileira com políticas de AA para admissão em universidades é relativamente recente, a literatura que investiga seus impactos ainda é limitada. Com relação aos efeitos da política sobre a matrícula de estudantesalvo, a maioria das pesquisas se restringe a experiências universitárias específicas. Exemplos de tais estudos incluem Cicalò (2008), Francis e Tannuri-Pianto (2012), 
Aranha, Pena e Ribeiro (2012) e Estevan, Gall e Morin (2016), cada um investigando os impactos de programas de AA adotados em diferentes universidades públicas, com importantes contribuições para se pensar, localmente, se os desenhos dos respectivos programas foram felizes em alcançar os resultados esperados. Para além da avaliação de uma experiência universitária isolada, Lopes (2016) examinou a distribuição de beneficiários das políticas de AA em diferentes cursos de instituições públicas. O estudo indica que os beneficiários das políticas estavam geralmente matriculados em cursos de menor prestígio (definidos em termos de retornos econômicos médios após a graduação). Embora o artigo investigue um grande conjunto de universidades, a análise é restrita a observações transversais dos cursos acadêmicos, isto é, a um único período temporal. Portanto, o autor não avaliou os impactos das políticas de AA na seleção de estudantes de grupos desfavorecidos ao longo do tempo.

De acordo com nossa revisão bibliográfica, nenhum outro estudo analisou os impactos gerais da introdução de políticas de AA em todas as universidades federais no período anterior à vigência da Lei de Cotas. Se, por um lado, a investigação de experiências universitárias individualizadas é fundamental para compreender em profundidade as especificidades de cada caso, os resultados dessas avaliações, por outro lado, podem estar contaminados por fatores não observados que sejam concomitantes à adoção das políticas de AA. Essa preocupação é particularmente sensível no cenário educacional das últimas décadas, em que inúmeras transformações aconteceram nas políticas de acesso nos setores público e privado e contribuíram para alterar a oferta e alocação das vagas, a demanda potencial e efetiva ao ensino superior, a relação candidato-vaga de determinados cursos e instituições etc. No entanto, ao compararmos o perfil de estudantes admitidos em universidades que adotaram políticas de AA com aqueles admitidos em universidades que não o fizeram, como proposto neste trabalho, somos capazes de contemplar fatores não observados, específicos de determinados períodos de tempo, que poderiam confundir as análises com base na experiência de uma única universidade ao longo dos anos ou de várias universidades em um único corte temporal.

Ademais, ao analisar as universidades que adotaram políticas de AA com diferentes populações-alvo, é possível cotejar os impactos de distintos desenhos de política. Um dos aspectos mais controversos das AA no Brasil é o uso de um critério racial, voltado à inclusão de estudantes negros e/ou indígenas a partir da autodeclaração (Daflon; Feres Júnior; Campos, 2013). Logo, compreender diferenças nos resultados entre programas com e sem critério racial é de suma importância para informar o debate sobre possíveis desenhos para uma política de justiça distributiva. No período analisado, 31 universidades adotaram algum tipo de programa de AA. Destas, 20 inclúram a cor/raça como critério de elegibilidade para acesso ao benefício e as 11 restantes adotaram programas de AA que definiam como beneficiários os estudantes do EMP, independentemente de sua cor ou raça. Para fins analíticos, classificaremos o 
primeiro grupo como programas de AA com critério racial e o segundo como programas de AA sem critério racial.

Sabe-se que a preferência das universidades brasileiras de adotar programas de AA voltados a egressos da rede pública se explica pela conhecida associação entre a dependência administrativa da rede de ensino e o nível socioeconômico do alunado que a frequenta (Osorio, 2009; Daflon; Feres Júnior; Campos, 2013), fenômeno que, além de fornecer um indicativo da condição socioeconômica do estudante, também provê uma informação menos controversa quanto ao critério de delimitação dos beneficiários, ao contrário do que acontece com a autodeclaração racial, recorrentemente sob a alegação da existência de fraudes. Porém, é preciso ter em mente que a correspondência entre cor/raça e renda familiar não necessariamente garante que políticas indiferentes à raça sejam eficazes em incluir estudantes negros e indígenas (Osorio, 2009). A título de ilustração, Darity, Deshpande e Weisskopf (2011) argumentam que programas de AA amparados em critérios de classe social são inerentemente menos eficazes do que os baseados em grupos populacionais específicos, caso o objetivo seja incrementar o acesso destes, especialmente quando este se dá por meio de alguma aferição de desempenho em testes. Entretanto, a magnitude desse diferencial no âmbito das universidades brasileiras é, em última instância, uma questão empírica. Assim, lançaremos mão da heterogeneidade em termos de critérios de elegibilidade dos desenhos de AA em nosso conjunto de dados para investigar se há contrastes entre os resultados de programas orientados ou indiferentes à raça, particularmente no que diz respeito a matrículas de negros e indígenas.

\section{BASES DE DADOS E METODOLOGIA}

\subsection{LINHA DO TEMPO DE ADOÇÃO DE AÇÕES AFIRMATTVAS NO BRASIL}

Sabendo que, no período antecedente à vigência da Lei de Cotas, as universidades federais usufruíam de autonomia para definir suas políticas de admissão de estudantes, nosso primeiro passo foi mapear os programas de AA adotados em cada instituição, identificando exatamente quando foram introduzidos e com base em quais critérios. O Quadro 1, originalmente construído por Vieira e Arends-Kuenning (2019), traz a linha do tempo de adoção de políticas de AA nas universidades federais. Em 2004, a UnB foi pioneira na adoção de uma política de AA para selecionar seus ingressantes. Nos anos que se seguiram, diversas outras implementaram tais políticas, cada qual com suas regras. Em 2013, por força da Lei de Cotas, todas as instituições federais passaram a adotar os critérios mínimos requisitados na legislação nacional. 


\section{QUADRO 1}

ANO DE ADOÇÃO DE PROGRAMAS DE AÇÃO AFIRMATIVA NAS UNIVERSIDADES FEDERAIS BRASILEIRAS

\begin{tabular}{|c|c|c|c|c|c|c|c|c|c|c|}
\hline Universidade & 2004 & 2005 & 2006 & 2007 & 2008 & 2009 & 2010 & 2011 & 2012 & 2013 \\
\hline $\mathrm{UnB}$ & $\mathrm{x}$ & $\mathrm{x}$ & $\mathrm{x}$ & $\mathrm{x}$ & $\mathrm{x}$ & $\mathrm{x}$ & $\mathrm{x}$ & $\mathrm{x}$ & $\mathrm{x}$ & $\mathrm{x}$ \\
\hline Ufal & & $\mathrm{x}$ & $\mathrm{x}$ & $\mathrm{x}$ & $\mathrm{x}$ & $\mathrm{x}$ & $\mathrm{x}$ & $\mathrm{x}$ & $\mathrm{x}$ & $\mathrm{x}$ \\
\hline UFBA & & $\mathrm{x}$ & $\mathrm{x}$ & $\mathrm{x}$ & $\mathrm{x}$ & $\mathrm{x}$ & $\mathrm{x}$ & $\mathrm{x}$ & $\mathrm{x}$ & $\mathrm{x}$ \\
\hline UFG & & $\mathrm{x}$ & $\mathrm{x}$ & $\mathrm{x}$ & $\mathrm{x}$ & $\mathrm{x}$ & $\mathrm{x}$ & $\mathrm{x}$ & $\mathrm{x}$ & $\mathrm{x}$ \\
\hline UFPR & & $\mathrm{x}$ & $\mathrm{x}$ & $\mathrm{x}$ & $\mathrm{x}$ & $\mathrm{x}$ & $\mathrm{x}$ & $\mathrm{x}$ & $\mathrm{x}$ & $\mathrm{x}$ \\
\hline UFRPE & & $\mathrm{x}$ & $\mathrm{x}$ & $\mathrm{x}$ & $\mathrm{x}$ & $\mathrm{x}$ & $\mathrm{x}$ & $\mathrm{x}$ & $\mathrm{x}$ & $\mathrm{x}$ \\
\hline Unifesp & & $\mathrm{x}$ & $\mathrm{x}$ & $\mathrm{x}$ & $\mathrm{x}$ & $\mathrm{x}$ & $\mathrm{x}$ & $\mathrm{x}$ & $\mathrm{x}$ & $\mathrm{x}$ \\
\hline UFT & & $\mathrm{x}$ & $\mathrm{x}$ & $\mathrm{x}$ & $\mathrm{x}$ & $\mathrm{x}$ & $\mathrm{x}$ & $\mathrm{x}$ & $\mathrm{x}$ & $\mathrm{x}$ \\
\hline UFJF & & & $\mathrm{x}$ & $\mathrm{x}$ & $\mathrm{x}$ & $\mathrm{x}$ & $\mathrm{x}$ & $\mathrm{x}$ & $\mathrm{x}$ & $\mathrm{x}$ \\
\hline UFPA & & & $\mathrm{x}$ & $\mathrm{x}$ & $\mathrm{x}$ & $\mathrm{x}$ & $\mathrm{x}$ & $\mathrm{x}$ & $\mathrm{x}$ & $\mathrm{x}$ \\
\hline UFPE & & & $\mathrm{x}$ & $\mathrm{x}$ & $\mathrm{x}$ & $\mathrm{x}$ & $\mathrm{x}$ & $\mathrm{x}$ & $\mathrm{x}$ & $\mathrm{x}$ \\
\hline UFRB & & & $\mathrm{x}$ & $\mathrm{x}$ & $\mathrm{x}$ & $\mathrm{x}$ & $\mathrm{x}$ & $\mathrm{x}$ & $\mathrm{x}$ & $\mathrm{x}$ \\
\hline UFRN & & & $\mathrm{x}$ & $\mathrm{x}$ & $\mathrm{x}$ & $\mathrm{x}$ & $\mathrm{x}$ & $\mathrm{x}$ & $\mathrm{x}$ & $\mathrm{x}$ \\
\hline UFABC & & & & $\mathrm{x}$ & $\mathrm{x}$ & $\mathrm{x}$ & $\mathrm{x}$ & $\mathrm{x}$ & $\mathrm{x}$ & $\mathrm{x}$ \\
\hline UFMA & & & & $\mathrm{x}$ & $\mathrm{x}$ & $\mathrm{x}$ & $\mathrm{x}$ & $\mathrm{x}$ & $\mathrm{x}$ & $\mathrm{x}$ \\
\hline UFPI & & & & $\mathrm{x}$ & $\mathrm{x}$ & $\mathrm{x}$ & $\mathrm{x}$ & $\mathrm{x}$ & $\mathrm{x}$ & $\mathrm{x}$ \\
\hline Ufes & & & & & $\mathrm{x}$ & $\mathrm{x}$ & $\mathrm{x}$ & $\mathrm{x}$ & $\mathrm{x}$ & $\mathrm{x}$ \\
\hline UFF & & & & & $\mathrm{x}$ & $\mathrm{x}$ & $\mathrm{x}$ & $\mathrm{x}$ & $\mathrm{x}$ & $\mathrm{x}$ \\
\hline UFRGS & & & & & $\mathrm{x}$ & $\mathrm{x}$ & $\mathrm{x}$ & $\mathrm{x}$ & $\mathrm{x}$ & $\mathrm{x}$ \\
\hline UFSC & & & & & $\mathrm{x}$ & $\mathrm{x}$ & $\mathrm{x}$ & $\mathrm{x}$ & $\mathrm{x}$ & $\mathrm{x}$ \\
\hline UFSCar & & & & & $\mathrm{x}$ & $\mathrm{x}$ & $\mathrm{x}$ & $\mathrm{x}$ & $\mathrm{x}$ & $\mathrm{x}$ \\
\hline UFSM & & & & & $\mathrm{x}$ & $\mathrm{x}$ & $\mathrm{x}$ & $\mathrm{x}$ & $\mathrm{x}$ & $\mathrm{x}$ \\
\hline UTFPR & & & & & $\mathrm{x}$ & $\mathrm{x}$ & $\mathrm{x}$ & $\mathrm{x}$ & $\mathrm{x}$ & $\mathrm{x}$ \\
\hline UFMG & & & & & & $\mathrm{x}$ & $\mathrm{x}$ & $\mathrm{x}$ & $\mathrm{x}$ & $\mathrm{x}$ \\
\hline Ufop & & & & & & $\mathrm{x}$ & $\mathrm{x}$ & $\mathrm{x}$ & $\mathrm{x}$ & $\mathrm{x}$ \\
\hline UFTM & & & & & & $\mathrm{x}$ & $\mathrm{x}$ & $\mathrm{x}$ & $\mathrm{x}$ & $\mathrm{x}$ \\
\hline UFRRJ & & & & & & & $\mathrm{x}$ & $\mathrm{x}$ & $\mathrm{x}$ & $\mathrm{x}$ \\
\hline UFS & & & & & & & $\mathrm{x}$ & $\mathrm{x}$ & $\mathrm{x}$ & $\mathrm{x}$ \\
\hline UFSJ & & & & & & & $\mathrm{x}$ & $\mathrm{x}$ & $\mathrm{x}$ & $\mathrm{x}$ \\
\hline Univasf & & & & & & & $\mathrm{x}$ & $\mathrm{x}$ & $\mathrm{x}$ & $\mathrm{x}$ \\
\hline URG & & & & & & & $\mathrm{x}$ & $\mathrm{x}$ & $\mathrm{x}$ & $\mathrm{x}$ \\
\hline UFPB & & & & & & & & $\mathrm{x}$ & $\mathrm{x}$ & $\mathrm{x}$ \\
\hline UFRJ & & & & & & & & $\mathrm{x}$ & $\mathrm{x}$ & $\mathrm{x}$ \\
\hline UFU & & & & & & & & $\mathrm{x}$ & $\mathrm{x}$ & $\mathrm{x}$ \\
\hline UFMT & & & & & & & & & $\mathrm{x}$ & $\mathrm{x}$ \\
\hline Ufac & & & & & & & & & & $\mathrm{x}$ \\
\hline
\end{tabular}




\section{ANO DE ADOÇÃO DE PROGRAMAS DE AÇÃO AFIRMATIVA NAS UNIVERSIDADES} FEDERAIS BRASILEIRAS

(conclusão)

\begin{tabular}{|c|c|c|c|c|c|c|c|c|c|c|}
\hline Universidade & 2004 & 2005 & 2006 & 2007 & 2008 & 2009 & 2010 & 2011 & 2012 & 2013 \\
\hline Ufam & & & & & & & & & & $\mathrm{x}$ \\
\hline UFC & & & & & & & & & & $\mathrm{x}$ \\
\hline UFCG & & & & & & & & & & $\mathrm{x}$ \\
\hline Ufla & & & & & & & & & & $\mathrm{x}$ \\
\hline UFMS & & & & & & & & & & $\mathrm{x}$ \\
\hline UFPEL & & & & & & & & & & $\mathrm{x}$ \\
\hline UFRR & & & & & & & & & & $\mathrm{x}$ \\
\hline UFV & & & & & & & & & & $\mathrm{x}$ \\
\hline Unifal & & & & & & & & & & $\mathrm{x}$ \\
\hline Unifap & & & & & & & & & & $\mathrm{x}$ \\
\hline Unifei & & & & & & & & & & $\mathrm{x}$ \\
\hline Unir & & & & & & & & & & $\mathrm{x}$ \\
\hline Unirio & & & & & & & & & & $\mathrm{x}$ \\
\hline
\end{tabular}

Fonte: Vieira e Arends-Kuenning (2019) com base nos editais de admissão das universidades.

Nota: Universidades ordenadas por período temporal e, dentro deste, por ordem alfabética. No Anexo A, detalhamos os programas adotados em cada instituição nesse período.

Os editais utilizados para construir essa linha do tempo permitem também mapear os critérios de seleção das políticas de AA de cada universidade. No período analisado, o principal tipo de programa de AA adotado foi a reserva de vagas. No total, 23 universidades federais implementaram esse tipo de política entre 2004 e 2010, período anterior à Lei de Cotas e para o qual os dados do Exame Nacional de Desempenho de Estudantes (Enade) dos ingressantes estão disponíveis, conforme discutiremos adiante. Nessas universidades, o percentual de vagas reservadas variou entre $5 \%$ e $50 \%$ do total, sendo a média igual a $35,6 \%$. Além disso, outras oito universidades adotaram, nesse mesmo período, programas de AA no formato de bônus. Nesse caso, em vez de uma proporção fixa de vagas, os alunos dos grupos beneficiários recebem um acréscimo na nota do vestibular. Nas universidades com esse tipo de programa, o bônus variou entre $10 \%$ e $20 \%{ }^{1}$

Além do tipo de AA, outra importante diferença entre as universidades foi a definição do público-alvo de cada programa. Em resumo, as universidades podem ser classificadas em 3 grupos principais:

1 - universidades que não adotaram nenhum tipo de AA no período;

1 O Quadro 2 (Anexo A) detalha os critérios de seleção utilizados nos programas de AA de cada universidade federal brasileira entre 2004 e 2012. 
2 - universidades que adotaram programas de AA sem critérios raciais;

3 - universidades que adotaram programas de AA com critérios raciais.

A Tabela 1 compara o quantitativo de universidades em cada um desses grupos conforme as políticas praticadas entre 2004 e 2010. Dentre 49 universidades federais, $31(63,3 \%)$ adotaram algum programa de AA - sendo 20 (40,8\%) com critério racial e $11(22,5 \%)$ sem critério racial - e 18 (36,7\%) não implementaram nenhum tipo de programa de AA no período.

TABELA 1

NÚMERO DE UNIVERSIDADES FEDERAIS POR TIPO DE POLÍTICA ADOTADA - BRASIL 2004-2010

\begin{tabular}{|l|c|c|}
\hline Tipo de política de ação afirmativa & $\begin{array}{c}\text { Número de } \\
\text { universidades }\end{array}$ & Proporção \\
\hline AA sem critério racial & 11 & $22,5 \%$ \\
\hline AA com critério racial & 20 & $40,8 \%$ \\
\hline Nenhuma política de AA & 18 & $36,7 \%$ \\
\hline
\end{tabular}

Fonte: Elaborada pelos autores com base em Vieira e Arends-Kuenning (2019).

\subsection{EXAME NACIONAL DE DESEMPENHO DE ESTUDANTES}

Esta investigação se circunscreve à primeira década de adoção de políticas de AA nas universidades federais, no entanto, é preciso reconhecer uma restrição metodológica importante: para o período analisado (2004-2012), não há nenhum banco de dados censitário que contenha características individualizadas dos estudantes matriculados em cada universidade. Para contornar essa limitação, nossa principal fonte de informação sobre os alunos ingressantes é o questionário socioeconômico do Enade, exame organizado e aplicado anualmente pelo Instituto Nacional de Estudos e Pesquisas Educacionais (Inep), obrigatório para alunos matriculados em universidades federais. O questionário do Enade é preenchido pelos próprios estudantes e inclui perguntas sobre características demográficas, socioeconômicas e relativas ao histórico educacional. Neste estudo, as variáveis selecionadas para análise foram: raça/cor, tipo de escola cursada no ensino médio, escolaridade dos pais e sexo.

Apesar de o nosso objetivo ser investigar as políticas adotadas antes de 2012, restringimos a análise ao período entre 2005 e 2010 por duas razões: (a) entre 2004 e 2010, a prova do Enade contava com a participação de alunos ingressantes; a partir de 2011, passaram a realizar o exame somente os alunos do último ano dos cursos selecionados. Além disso, (b) outra limitação é que os cursos são divididos em três grupos, e cada grupo é avaliado a cada três anos. Dessa forma, os cursos são avaliados em ciclos trienais. Para que a análise contenha um número consistente de 
observações para todos os cursos, excluímos as observações de 2004 (ano em que proporcionalmente a amostra de participantes era menor), permanecendo assim com dois ciclos de observações (2005-2007 e 2008-2010) para todos os cursos avaliados. A Tabela 2 mostra os principais cursos de graduação incluídos em cada rodada do Enade entre 2005 e 2010, com o número de calouros de universidades federais a cada ano.

TABELA 2

\section{AMOSTRA DE CALOUROS DE UNIVERSIDADES FEDERAIS OBSERVADOS NAS PROVAS DO ENADE, POR ANO E CURSO DE GRADUAÇÃO - BRASIL - 2005-2010}

\begin{tabular}{|c|c|c|c|c|c|c|c|}
\hline \multicolumn{8}{|r|}{ (continu } \\
\hline Curso & 2005 & 2006 & 2007 & 2008 & 2009 & 2010 & Total \\
\hline \multicolumn{8}{|l|}{ Grupo 1} \\
\hline Medicina & - & - & 1.527 & - & - & 5.167 & 6.694 \\
\hline Agronomia & - & - & 1.931 & - & - & 3.983 & 5.914 \\
\hline Enfermagem & - & - & 1.619 & - & - & 3.974 & 5.593 \\
\hline Farmácia & - & - & 1.073 & - & - & 3.037 & 4.110 \\
\hline Serviços sociais & - & - & 1.054 & - & - & 3.026 & 4.080 \\
\hline Educação física & - & - & 1.834 & - & - & 1.624 & 3.458 \\
\hline Veterinária & - & - & 1.198 & - & - & 2.636 & 3.834 \\
\hline Odontologia & - & - & 948 & - & - & 2.349 & 3.297 \\
\hline Zootecnia & - & - & 1.268 & - & - & 2.068 & 3.336 \\
\hline Nutrição & - & - & 932 & - & - & 2.256 & 3.188 \\
\hline Fisioterapia & - & - & 293 & - & - & 1.244 & 1.537 \\
\hline Fonoaudiologia & - & - & 119 & - & - & 513 & 632 \\
\hline \multicolumn{8}{|l|}{ Grupo 2} \\
\hline Engenharia & 8.052 & - & - & 13.285 & - & - & 21.337 \\
\hline Letras & 3.369 & - & - & 4.033 & - & - & 7.402 \\
\hline Pedagogia & 2.470 & - & - & 4.578 & - & - & 7.048 \\
\hline Matemática & 2.146 & - & - & 3.535 & - & - & 5.681 \\
\hline Biologia & 1.603 & - & - & 3.995 & - & - & 5.598 \\
\hline Química & 1.495 & - & - & 3.134 & - & - & 4.629 \\
\hline História & 1.934 & - & - & 2.598 & - & - & 4.532 \\
\hline Computação & 1.612 & - & - & 2.864 & - & - & 4.476 \\
\hline Física & 1.674 & - & - & 2.710 & - & - & 4.384 \\
\hline Geografia & 1.254 & - & - & 2.147 & - & - & 3.401 \\
\hline Ciências sociais & 1.182 & - & - & 1.822 & - & - & 3.004 \\
\hline Filosofia & 756 & - & - & 1.320 & - & - & 2.076 \\
\hline Arquitetura & 510 & - & - & 1.182 & - & - & 1.692 \\
\hline \multicolumn{8}{|l|}{ Grupo 3} \\
\hline Administração & - & 2.633 & - & - & 8.780 & - & 11.413 \\
\hline Direito & - & 2.245 & - & - & 6.097 & - & 8.342 \\
\hline
\end{tabular}


TABELA 2

\section{AMOSTRA DE CALOUROS DE UNIVERSIDADES FEDERAIS OBSERVADOS NAS PROVAS DO ENADE, POR ANO E CURSO DE GRADUAÇÃO - BRASIL - 2005-2010}

\begin{tabular}{|l|c|c|c|c|c|c|c|}
\hline \multicolumn{1}{|c|}{ Curso } & $\mathbf{2 0 0 5}$ & $\mathbf{2 0 0 6}$ & $\mathbf{2 0 0 7}$ & $\mathbf{2 0 0 8}$ & $\mathbf{2 0 0 9}$ & $\mathbf{2 0 1 0}$ & Total \\
\hline Economia & - & 2.016 & - & - & 4.592 & - & 6.608 \\
\hline Contabilidade & - & 1.773 & - & - & 4.305 & - & 6.078 \\
\hline Comunicação & - & 1.674 & - & - & 2.761 & - & 4.435 \\
\hline Psicologia & - & 1.261 & - & - & 2.620 & - & 3.881 \\
\hline Biblioteconomia & - & 1.172 & - & - & 1.815 & - & 2.987 \\
\hline Música & - & 742 & - & - & 2.167 & - & 2.909 \\
\hline Turismo & - & 605 & - & - & 1.136 & - & 1.741 \\
\hline $\begin{array}{l}\text { Design } \\
\text { Dramaturgia }\end{array}$ & - & 568 & - & - & 1.119 & - & 1.687 \\
\hline $\begin{array}{l}\text { Secretariado } \\
\text { executivo }\end{array}$ & - & 536 & - & - & 997 & - & 1.533 \\
\hline
\end{tabular}

Fonte: Elaborada pelos autores com base em Vieira e Arends-Kuenning (2019).

A respeito desse contingente, a Tabela 3 apresenta a distribuição das variáveis selecionadas na amostra de calouros que fizeram o Enade no período, isto é, entre 2005 e 2010. Os alunos brancos eram a maioria (59,6\%), seguidos por pardos $(31,0 \%)$ e pretos (6,7\%). Quase metade desses alunos cursou todo o ensino médio em escolas privadas (48,7\%), enquanto 41\% estudaram sempre em escolas públicas e 10,3\% estudaram parcialmente em ambos os tipos de escola. Para quase metade desses alunos $(47,5 \%)$ ou o pai ou a mãe possuíam ensino superior completo, e para $20,7 \%$ nem o pai nem a mãe haviam concluído o ensino médio. Por fim, pouco mais da metade dessa amostra (51,8\%) era composta por mulheres.

TABELA 3

\section{CARACTERÍSTICAS DESCRITIVAS DOS CALOUROS DE UNIVERSIDADES FEDERAIS, DE ACORDO COM O QUESTIONÁRIO DO ENADE - BRASIL - 2004-2010}

(continua)

\begin{tabular}{|c|c|c|c|}
\hline & \multirow{2}{*}{ Observações } & \multicolumn{2}{|c|}{ Proporção } \\
\hline & & Total & (Exceto ND) \\
\hline \multicolumn{4}{|l|}{ Raça/cor } \\
\hline Branco & 59.130 & $35,8 \%$ & $59,6 \%$ \\
\hline Preto & 6.601 & $4,0 \%$ & $6,7 \%$ \\
\hline Pardo & 30.785 & $18,6 \%$ & $31,0 \%$ \\
\hline Amarelo & 1.561 & $0,9 \%$ & $1,6 \%$ \\
\hline Indígena & 1.099 & $0,7 \%$ & $1,1 \%$ \\
\hline $\mathrm{ND}^{*}$ & 65.963 & $39,9 \%$ & - \\
\hline
\end{tabular}


TABELA 3

\section{CARACTERÍSTICAS DESCRITIVAS DOS CALOUROS DE UNIVERSIDADES FEDERAIS, DE ACORDO COM O QUESTIONÁRIO DO ENADE - BRASIL - 2004-2010}

(conclusão)

\begin{tabular}{|c|c|c|c|}
\hline & \multirow{2}{*}{ Observações } & \multicolumn{2}{|c|}{ Proporção } \\
\hline & & Total & (Exceto ND) \\
\hline \multicolumn{4}{|l|}{ Ensino médio } \\
\hline Todo em escola pública & 40.711 & $24,7 \%$ & $41,0 \%$ \\
\hline Parcial (pública/privada) & 10.206 & $6,2 \%$ & $10,3 \%$ \\
\hline Todo em escola privada & 48.332 & $29,3 \%$ & $48,7 \%$ \\
\hline $\mathrm{ND}^{*}$ & 65.890 & $39,9 \%$ & - \\
\hline \multicolumn{4}{|l|}{ Máxima escolaridade dos pais } \\
\hline Nenhuma/analfabetos & 1.261 & $0,8 \%$ & $1,3 \%$ \\
\hline $4^{\mathrm{a}}$ série fundamental & 10.162 & $6,2 \%$ & $10,2 \%$ \\
\hline $8^{\mathrm{a}}$ série fundamental & 9.100 & $5,5 \%$ & $9,2 \%$ \\
\hline Ensino médio & 31.688 & $19,2 \%$ & $31,9 \%$ \\
\hline Ensino superior & 47.162 & $28,6 \%$ & $47,5 \%$ \\
\hline $\mathrm{ND}^{*}$ & 65.766 & $39,8 \%$ & - \\
\hline \multicolumn{4}{|l|}{ Sexo } \\
\hline Feminino & 84.529 & $51,8 \%$ & $51,8 \%$ \\
\hline Masculino & 80.610 & $48,2 \%$ & $48,2 \%$ \\
\hline $\mathrm{ND}^{*}$ & 0 & $0,0 \%$ & - \\
\hline
\end{tabular}

Fonte: Elaborada pelos autores com base em Vieira e Arends-Kuenning (2019).

Nota: A amostra inclui todos os calouros de universidades federais que fizeram o Enade entre 2005 e 2010.

*Não disponível.

Assim, a amostra total analisada inclui 163.364 ingressantes de universidades federais que participaram do Enade entre 2005 e 2010². Para estudar as alterações no perfil desse conjunto, organizamos a amostra em 2.050 coortes, em que cada coorte é definida como os alunos ingressantes em um determinado curso e universidade em um dado ano, por exemplo, os ingressantes do curso de Direito da UnB em 2006. Ao todo, esses estudantes estavam inscritos em 1.025 cursos de graduação de 47 universidades federais e, para cada coorte, avaliou-se em média 79,1 estudantes. Nota-se que o número de programas é exatamente metade do número de coortes

\footnotetext{
2 Segundo dados do Censo da Educação Superior, entre 2005 e 2010 ingressaram nas universidades federais brasileiras 914.316 alunos. Apesar de o Enade ser obrigatório para os estudantes de instituições federais, a amostra do nosso estudo não é equivalente a esse total por conta dos seguintes motivos: 1) nem todas as graduações acadêmicas estão incluídas no Enade; 2) cada programa é avaliado trienalmente, logo, mesmo para os cursos englobados no exame, a amostra inclui apenas os ingressantes dos anos avaliados; 3) o exame acontece no final do ano, portanto, os alunos que abandonaram o curso entre a matrícula e a data de realização também não são incluídos. Ainda assim, a amostra utilizada representa um importante conjunto de dados, de abrangência nacional, com informações individualizadas dos estudantes no período analisado.
} 
porque a amostra foi restrita somente aos programas observados em ambos os ciclos do Enade que compõem o período da análise.

\section{ALTERAÇÕES NO PERFIL DISCENTE DOS INGRESSANTES}

Para a análise descritiva da relação entre a adoção de políticas de AA e as mudanças no perfil dos ingressantes nas universidades federais, este trabalho compara a evolução do percentual de estudantes com determinadas características socioeconômicas em programas que adotaram algum tipo de AA (definidos como grupo tratado) com a variação equivalente observada em programas que não adotaram nenhuma política de AA no mesmo período (definidos como grupo controle).

O primeiro passo consistiu em selecionar os cursos que participaram de dois ciclos consecutivos do Enade - por exemplo, os ingressantes das turmas de Medicina da UFRJ que participaram do Enade tanto em 2007 quanto em 2010. Para cada um desses cursos, as coortes do primeiro ciclo (2005-2007) foram definidas como pertencentes ao primeiro período e as do segundo ciclo (2008-2010) como pertencentes ao segundo período.

O segundo passo tratou de diferenciar os cursos que compõem o grupo tratado e os que compõem o grupo controle. Tal definição foi feita conforme o seguinte critério: chamaremos de grupo tratado os cursos que não adotaram programas de AA no primeiro período, mas o fizeram no segundo; e chamaremos de grupo controle os cursos que não adotaram programas de AA em ambos os períodos. Já os cursos com programas de AA em ambos os períodos foram excluídos da análise.

$\mathrm{Na}$ terceira etapa, calculou-se o percentual de alunos em cada coorte com as seguintes características: negros (autodeclarados pretos ou pardos), ensino médio em escola pública (cursaram todo o ensino médio na rede pública), pais sem educação secundária (máxima escolaridade parental é inferior ao ensino médio completo) e mulheres.

A partir dessas classificações, comparamos a evolução média de ingressantes com cada uma dessas características entre o primeiro e o segundo período, em seguida, contrastando a variação observada no grupo controle e no grupo tratado.

A Tabela 4 mostra o resultado geral da análise. Cada coluna corresponde a uma das quatro variáveis definidas anteriormente. As linhas (1), (2), (4) e (5) indicam a média ponderada da proporção de alunos pertencentes a cada uma dessas variáveis por grupo de tratamento do curso e por período. Por exemplo, os cursos do grupo controle possuíam em média $38,4 \%$ de alunos negros no primeiro período, e essa proporção passou a ser de 39,1\% no segundo período. Já nos cursos do grupo tratado, tal proporção variou de 30,9\% no primeiro período para 34,1\% no segundo. 
TABELA 4

\section{VARIAÇÃO NA PROPORÇÃO DE INGRESSANTES DE UNIVERSIDADES FEDERAIS COM CARACTERÍSTICAS SOCIOECONÔMICAS ADVERSAS, POR GRUPO DE TRATAMENTO DOS CURSOS - BRASIL - 2005-2010}

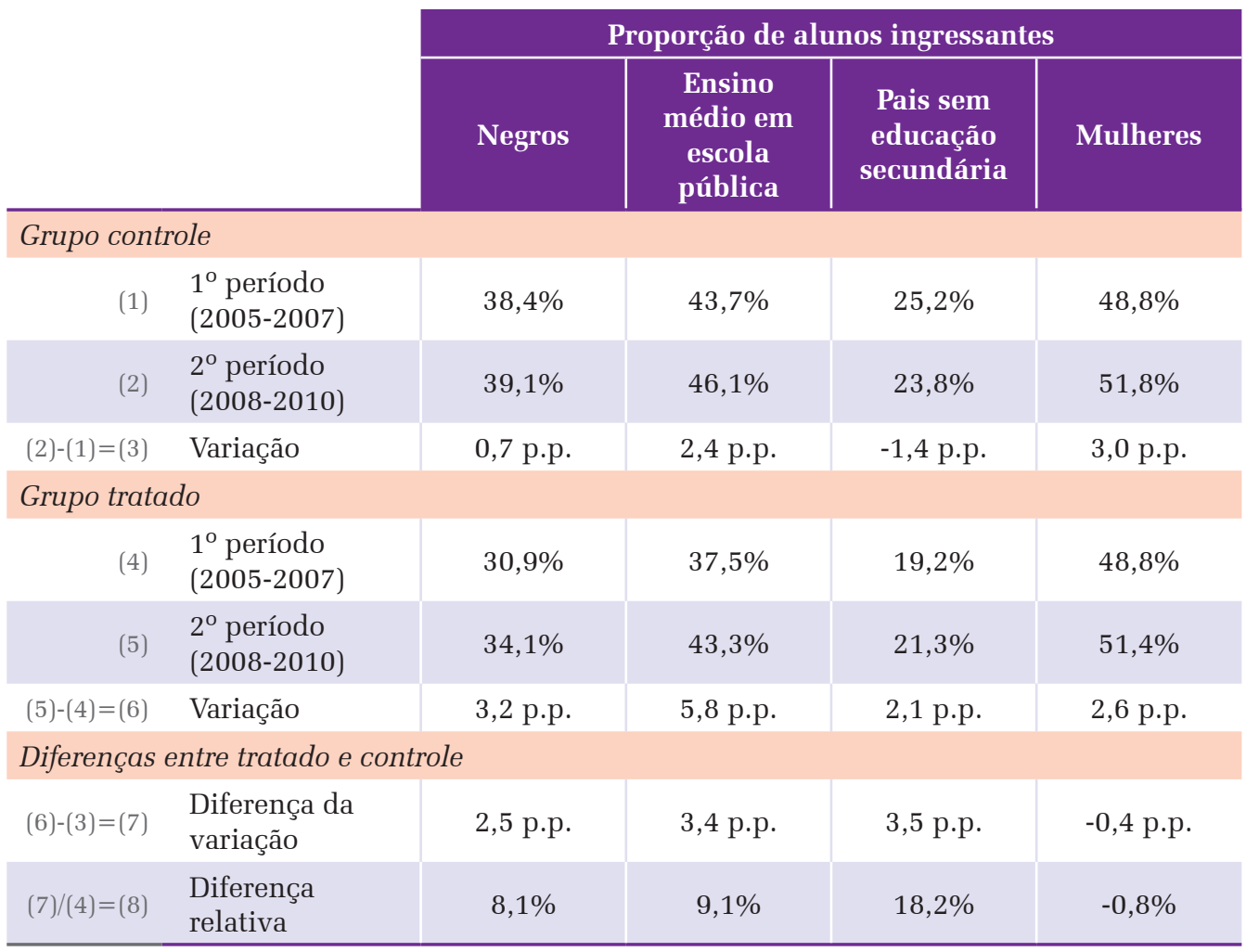

Fonte: Elaborada pelos autores com base em dados do Enade 2005-2010.

Nota: O grupo controle é definido pelos programas que não possuíam AA tanto no $1^{\circ}$ quanto no $2^{\circ}$ período. O grupo tratado inclui programas sem AA no $1^{\circ}$ período, mas que adotaram AA no $2^{\circ}$. As médias foram calculadas ponderando-se os cursos pelo total de alunos observados em cada coorte.

As linhas (3) e (6) da Tabela 4 apontam a variação média absoluta de cada variável observada nos grupos. No caso do grupo controle, a maior variação ocorreu no percentual de mulheres, que aumentou três pontos percentuais (p.p.) entre os períodos estudados. Já o percentual de alunos cujos pais não possuem o ensino médio completo caiu 1,4 p.p. No caso do grupo tratado, a maior variação absoluta foi do total de alunos que cursaram todo o ensino médio em escolas públicas, o qual aumentou 5,8 p.p. no período.

As linhas (7) e (8) se relacionam com as diferenças da variação observada entre ambos os grupos. A linha (7) apresenta a diferença absoluta, calculada pela subtração entre a variação observada no grupo tratado e a variação observada no grupo controle. Os resultados dessa comparação indicam que, para três dos quatro grupos - alunos negros, alunos provenientes da rede pública e alunos cujos pais não 
completaram o ensino médio -, houve maiores incrementos nos cursos que adotaram programas de AA se comparados aos cursos que não os adotaram. Tal diferença foi de, respectivamente, 2,5, 3,4 e 3,5 p.p. Já com relação ao total de mulheres, a diferença foi negativa, ainda que de apenas -0,4 p.p. A linha (8) traduz essas diferenças em termos relativos, isto é, qual o significado dessa diferença com relação aos percentuais de cada variável observados no primeiro período. Os resultados calculados nessa linha mostram que a variação adicional observada nos cursos tratados com programas de AA corresponderia a um aumento de respectivamente $8,1 \%$ no total de alunos negros, $9,1 \%$ no total de alunos de escolas públicas e 18,2\% no total de alunos cujos pais não completaram o ensino médio.

Por fim, para analisar os resultados além das médias de cada grupo, a Figura 1 expõe a variação nas distribuições de cada variável entre o primeiro e segundo períodos para os grupos controle e tratado. Destaca-se o deslocamento para a direita nas distribuições do grupo tratado para o total de alunos negros, cujos pais não completaram o ensino médio e, principalmente, no percentual de alunos de escola pública. No caso do grupo tratado, as variações nas distribuições entre os períodos são menos evidentes.

Em resumo, a análise apresentada nesta seção revela que, nos cursos em que programas de AA foram adotados, houve aumento na participação de alunos com condições socioeconômicas adversas, além de uma pequena redução na presença de mulheres ${ }^{3}$. Esse aumento foi maior do que a variação equivalente observada em programas nos quais nenhum tipo de política de AA foi adotada. Nas próximas seções, expandimos essa análise avaliando os casos de alguns cursos específicos e as diferenças entre programas de AA distintos.

\footnotetext{
3 Esse resultado indica, por dedução, que houve incremento na presença de homens, fenômeno coerente com o aumento na proporção de ingressantes com características adversas - como a literatura educacional tem destacado, homens são minoria no acesso ao ensino superior na maior parte dos países desenvolvidos e em desenvolvimento (Carvalho, 2008; Unesco, 2012).
} 
PAINEL A: Negros

GRUPO CONTROLE

sem AA em ambos os períodos

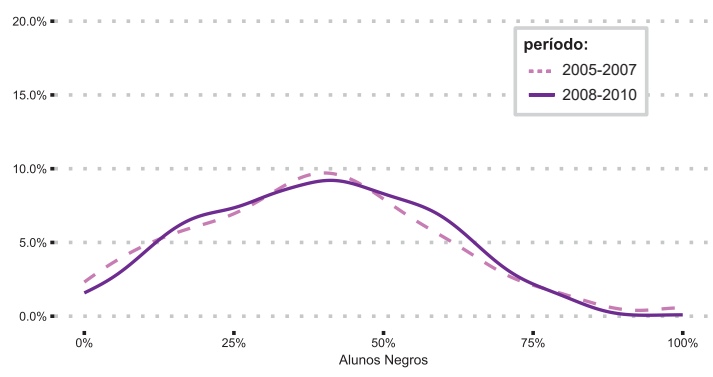

GRUPO TRATADO

sem AA no $1^{\circ}$ periodo, com AA no $2^{\circ}$

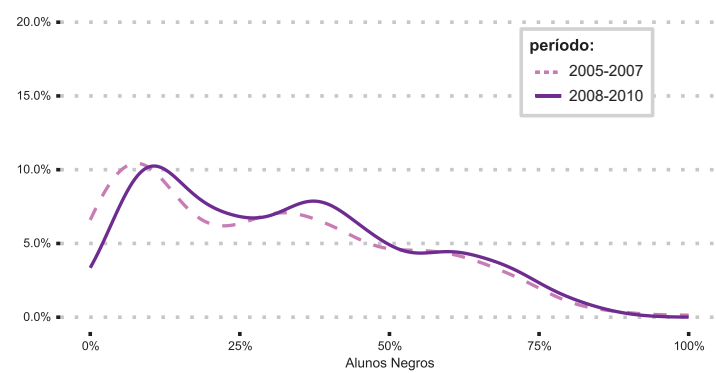

PAINEL B: Escola Pública

GRUPO CONTROLE

sem $A A$ em ambos os períodos

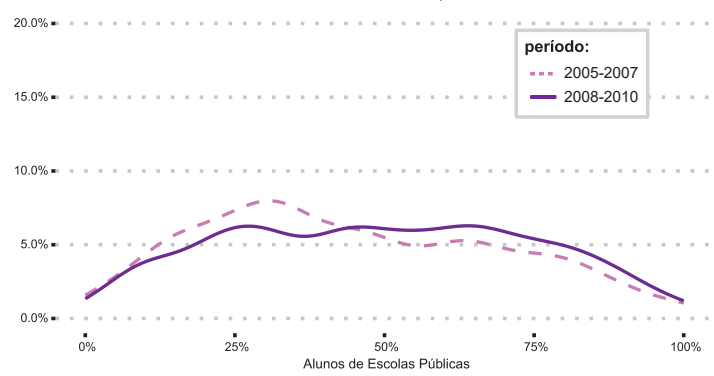

PAINEL C: Educ. dos Pais

GRUPO CONTROLE sem AA em ambos os períodos

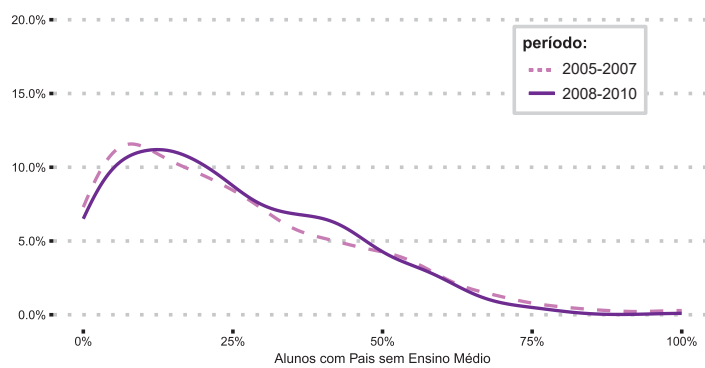

PAINEL D: Mulheres

GRUPO CONTROLE sem AA em ambos os periodos

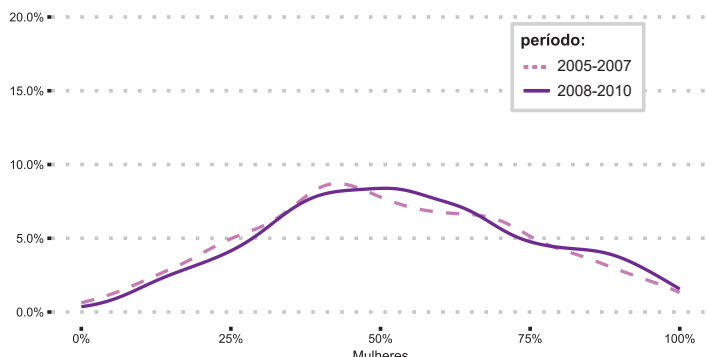

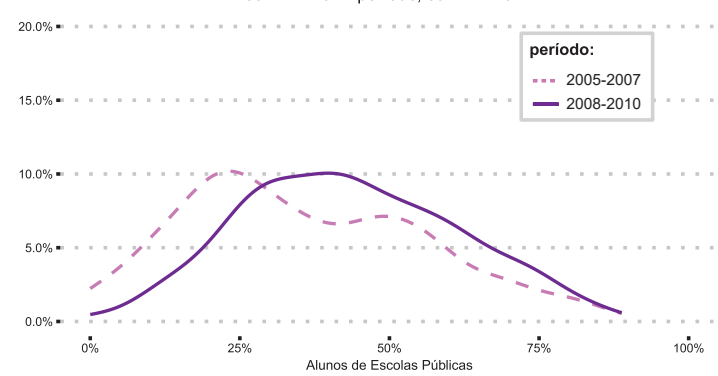

GRUPO TRATADO

sem $A A$ no $1^{\circ}$ período, com AA no $2^{\circ}$

sem AA no $1^{\circ}$ período, com AA no $2^{\circ}$

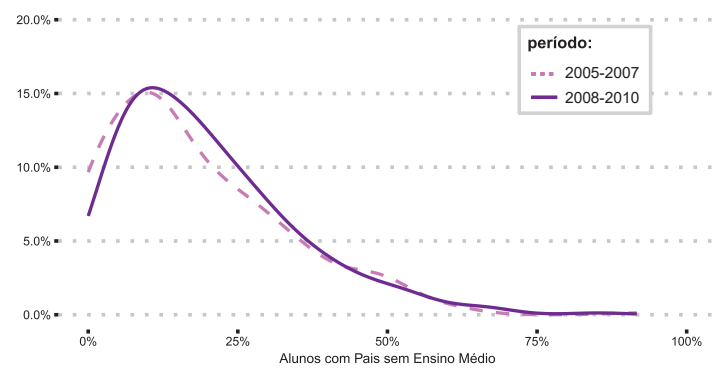
sem AA no $1^{\circ}$ período, com $A A$ no $2^{\circ}$

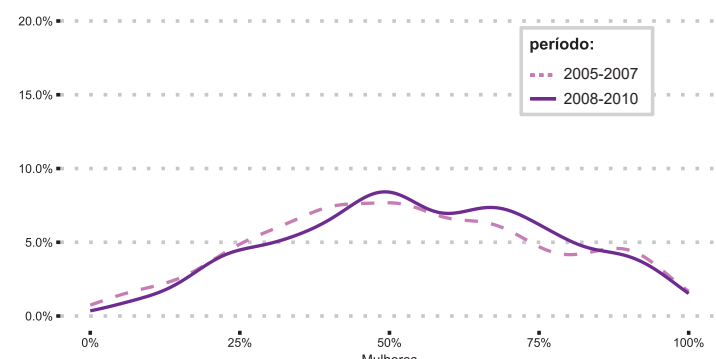

FIGURA 1

DISTRIBUIÇÃO DAS VARIÁVEIS ESTUDADAS POR PERÍODO E POR GRUPO DE TRATAMENTO - BRASIL - 2005-2010

Fonte: Elaborada pelos autores com base em dados do Enade 2005-2010. 


\subsection{HETEROGENEIDADE DOS RESULTADOS EM DIFERENTES CURSOS}

A primeira extensão da análise se refere às variações observadas em diferentes carreiras. Para tanto, selecionamos quatro dentre os cursos mais tradicionais e com as maiores quantidades de alunos: Medicina, Direito, Letras e Engenharia. Esses cursos foram escolhidos por possuírem níveis de competitividade bastante distintos, a partir da distribuição das notas de corte de cada uma dessas carreiras no Sistema de Seleção Unificada (Sisu) de 2016. ${ }^{4}$ Menos concorridos, os cursos de Letras apresentam uma nota de corte média de apenas 635,1 pontos no Enem. Em seguida, temos os cursos de Engenharia com uma nota de corte média de 698,3 pontos e Direito com 741,2 pontos. Os cursos de Medicina possuem as maiores notas de corte: 795,4 pontos. Para efeito de comparação, os demais cursos possuem uma nota de corte média de apenas 666,9 pontos.

A Tabela 5 apresenta uma análise equivalente à da Tabela 4, dessa vez calculada separadamente para cada uma das carreiras. Observa-se que as maiores diferenças entre os grupos tratado e controle ocorrem no caso dos cursos de Medicina, em que a proporção de alunos de escolas públicas nas universidades que adotaram AA saltou de $9,2 \%$ no primeiro período para $27,6 \%$ no segundo. Essa variação representa um crescimento relativo de $250 \%$ quando comparada à variação observada no grupo controle (4,7 p.p). Ainda sobre os cursos de Medicina, o número de alunos cujos pais não completaram o ensino médio demonstrou um crescimento relativo de grande magnitude (+101\%). No caso dos cursos de Direito, um padrão bastante semelhante, mas de menor intensidade, também foi observado, sendo o crescimento referente ao total de alunos de escola pública a diferença mais relevante $(+49,9 \%)$.

Já nas carreiras de Engenharia e Letras, as diferenças relativas entre os grupos tratado e controle foram menores, sendo os efeitos absolutos praticamente desprezíveis. É interessante notar que, no caso dos cursos de Letras, há uma razoável redução $(-14,2 \%)$ no total de alunos negros no grupo tratado com programas de AA em relação ao grupo controle, o que poderia indicar a possibilidade de mudanças nas escolhas das carreiras selecionadas pelos alunos negros após a adoção dos programas de AA, migrando dos cursos menos para os mais competitivos.

É importante notar que, para todas as variáveis analisadas, com exceção do percentual de mulheres, a proporção de alunos no primeiro período (antes dos programas de $\mathrm{AA}$ ) era inversamente proporcional à competitividade média dos programas. Isto é, a proporção de alunos negros, de escola pública e cujos pais não concluíram o ensino médio era menor nos cursos de Medicina e gradativamente maior nos cursos de Direito, Engenharia e Letras. Tal diferença pode explicar, em parte, a menor margem para variações relativas após os programas de AA nos cursos pouco competitivos.

\footnotetext{
4 Foi utilizada a nota de corte no Sisu 2016 para essa comparação por duas razões: (1) no período estudado, cada universidade possuía sua própria prova de seleção, já no Sisu, todos os alunos têm a nota baseada na mesma prova (Enem), o que permite uma comparação direta entre diferentes cursos de distintas universidades; (2) a partir de 2016, todas as universidades passaram a aplicar integralmente a reserva de vagas definidas pela Lei de Cotas. Sendo assim, a nota de corte de cada curso em 2016 não é afetada pelo fato de possuírem ou não diferentes políticas de AA.
} 


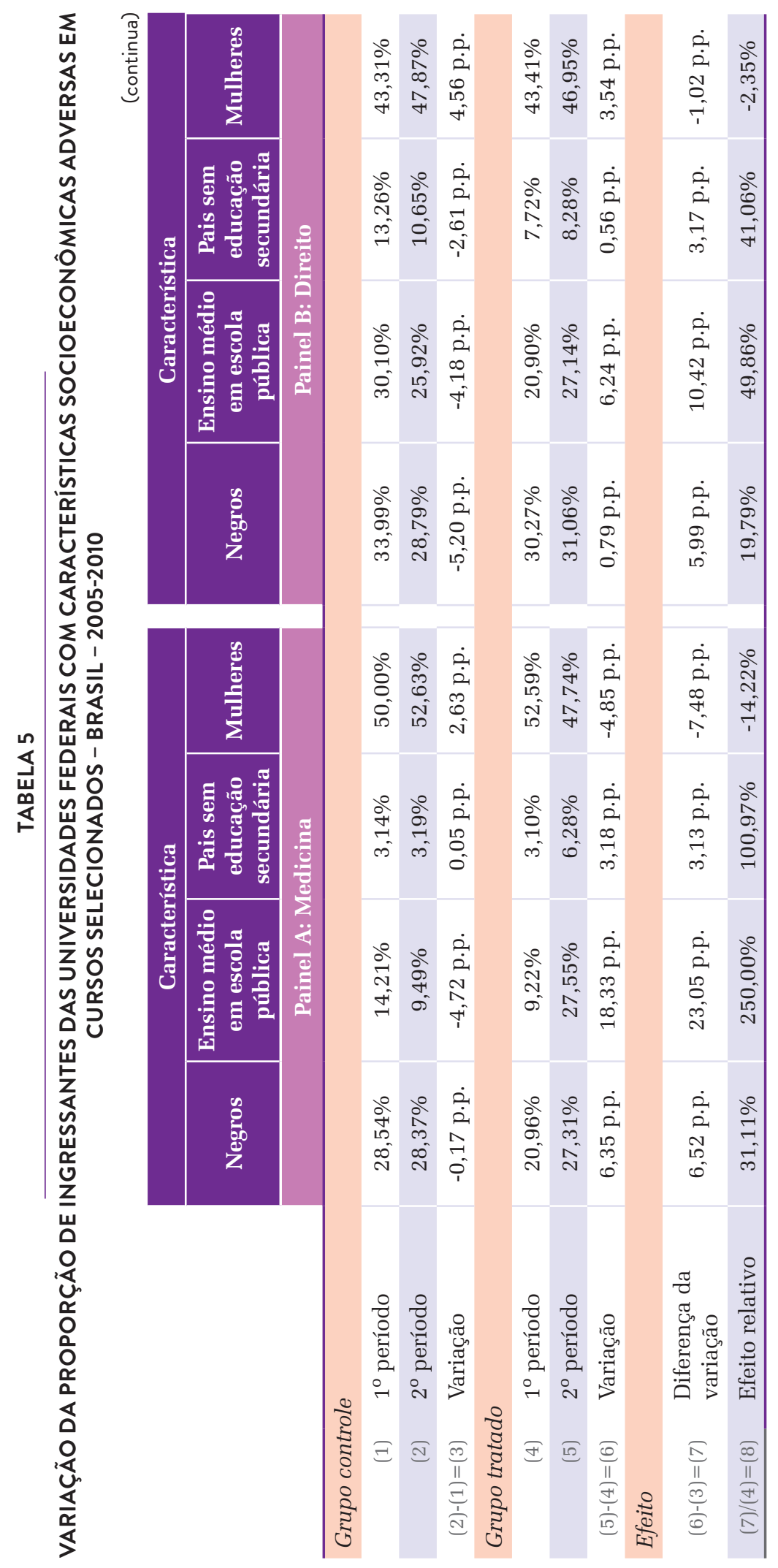




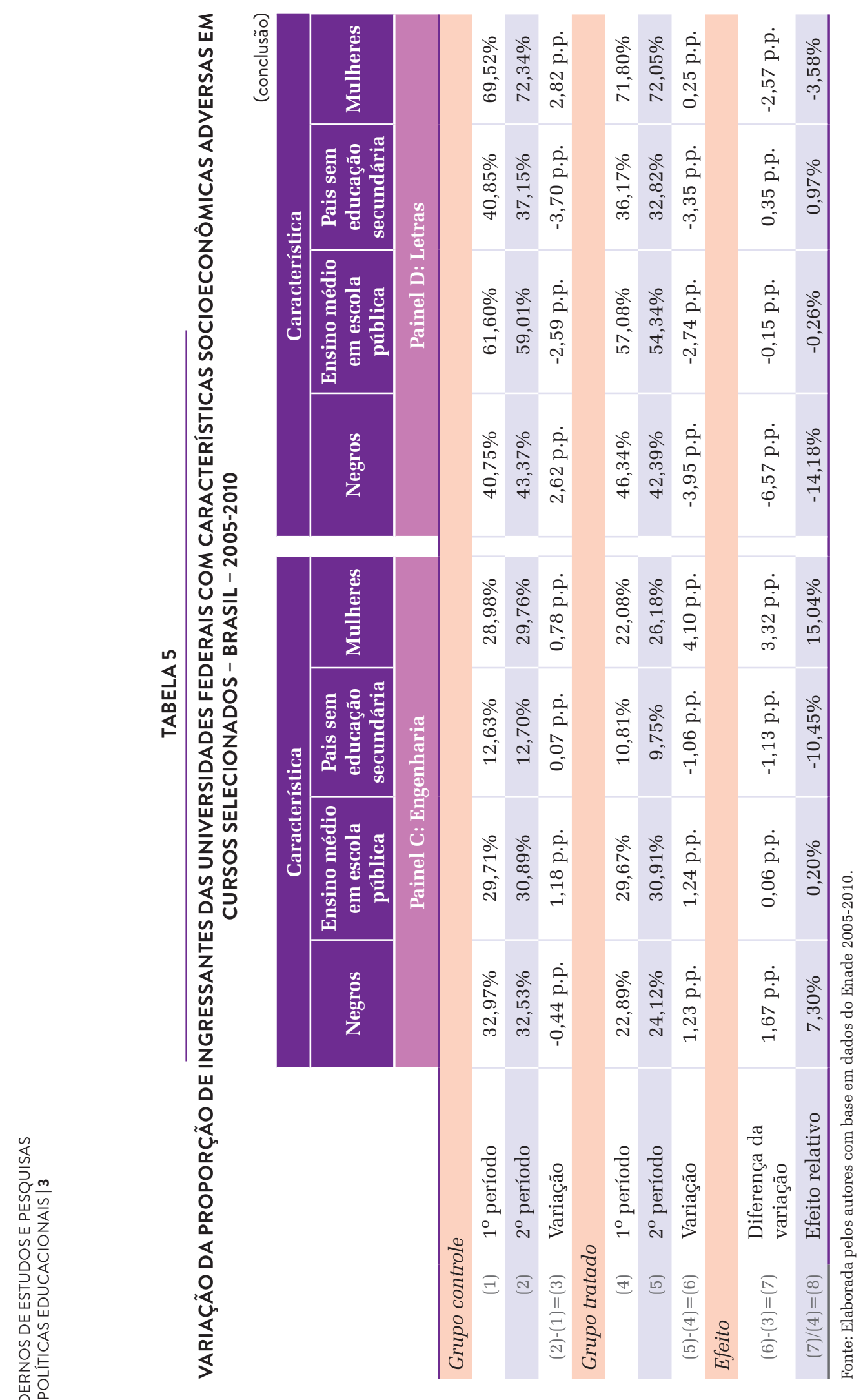


Em síntese, os resultados apontam que as principais mudanças no perfil dos ingressantes após a adoção de políticas de AA ocorreram nas carreiras mais competitivas e foram praticamente nulas nos cursos de menor competividade, nos quais mesmo antes das políticas de AA o percentual de alunos com características socioeconômicas desfavorecidas já era relativamente mais alto.

\subsection{HETEROGENEIDADE DOS RESULTADOS POR TIPO DE AA}

Conforme descrito, as políticas de AA adotadas no período estudado podem ser diferenciadas em dois subgrupos principais: programas de AA com critérios raciais e sem critérios raciais. Embora tais políticas possam ser classificadas em inúmeras tipologias, centraremos esforços sobre a comparação destas em relação à adoção ou não de um critério baseado na raça/cor do candidato em função das polêmicas existentes na sociedade quanto à adequação desse tipo de recorte para delimitação de beneficiários. Para averiguar essa questão, o estudo estendeu a análise apresentada na Tabela 4 desagregando o grupo tratado em dois subgrupos: (a) os cursos que adotaram programas de AA com critérios raciais e (b) os cursos que adotaram programas de AA sem critérios raciais. A comparação das diferenças entre esses grupos é exposta na Tabela 6.

Ao que tange nossa pergunta de pesquisa, a discussão mais relevante se refere à variação no total de ingressantes negros. Observa-se que, no grupo tratado com critérios raciais, a variação relativa em comparação ao grupo controle foi positiva e de aproximadamente $+16,86 \%$. Já no grupo tratado sem critérios raciais, a variação no percentual de alunos negros entre o primeiro e segundo períodos foi, em realidade, negativa e inferior ao grupo controle.

Com relação ao total de alunos que cursaram o ensino médio em escolas públicas, o efeito em ambos os grupos de tratamento foi bastante semelhante e, no caso dos alunos cujos pais não completaram o ensino médio, a variação relativa ao grupo controle também foi positiva para ambos os grupos tratados, apesar de a diferença ter sido maior no caso dos cursos em que os programas de AA não tinham critério racial. A variação no percentual de mulheres novamente não foi relevante. 
TABELA 6

\section{VARIAÇÃO DA PROPORÇÃO DE INGRESSANTES DAS UNIVERSIDADES FEDERAIS COM CARACTERÍSTICAS SOCIOECONOMMICAS ADVERSAS, SEGUNDO O TIPO DE PROGRAMA DE AA - BRASIL - 2005-2010}

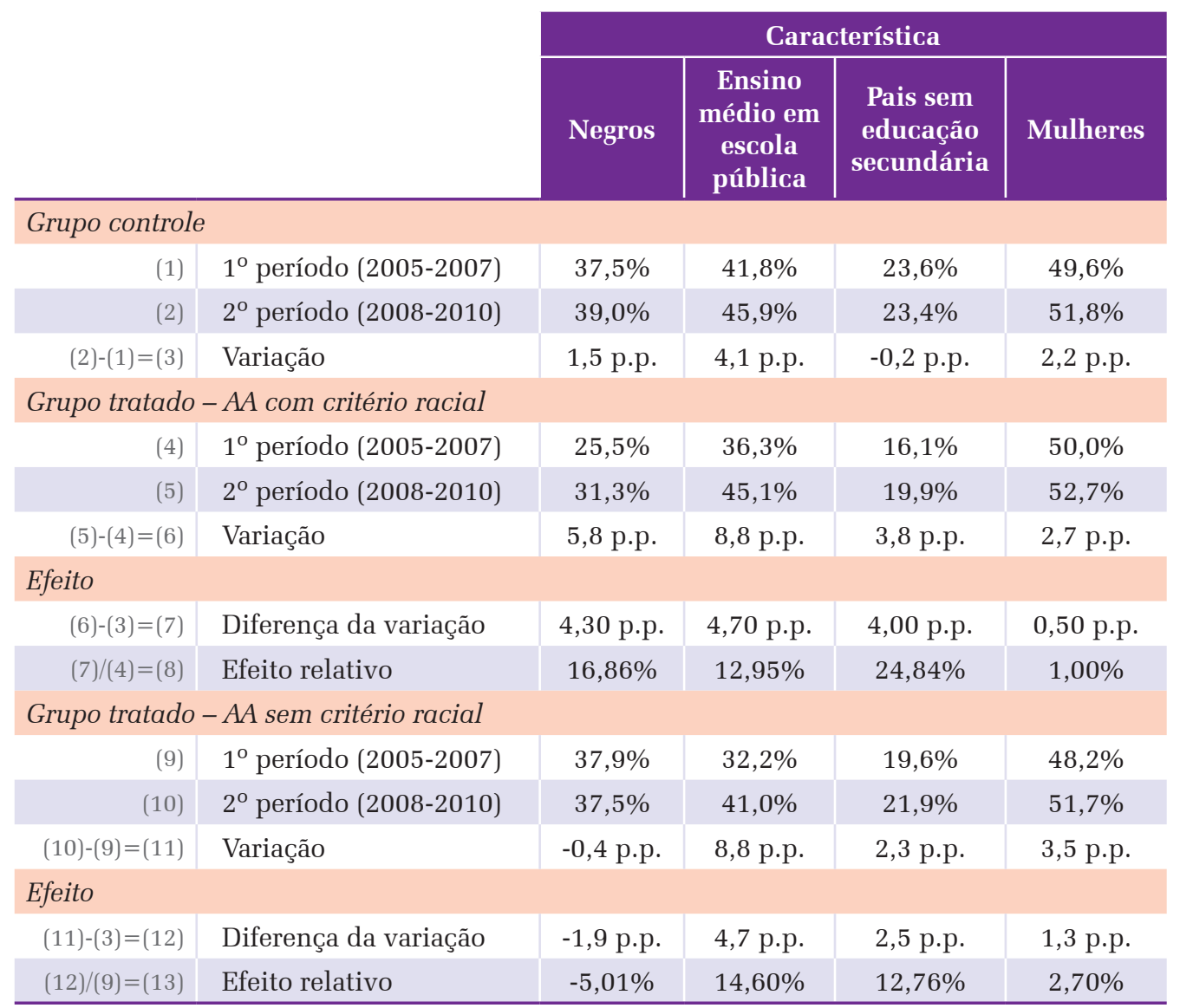

Fonte: Elaborada pelos autores com base em dados do Enade 2005-2010.

Por fim, a Figura 2 apresenta a variação na distribuição do total de alunos negros entre os dois períodos em cada um dos grupos de tratamento definidos. Nota-se um claro deslocamento para a direita no caso dos programas que adotaram políticas de AA com critério racial. Enquanto isso, tanto no grupo controle quanto nos programas que adotaram AA sem critério racial, a variação entre ambos os períodos foi bem mais tênue. 

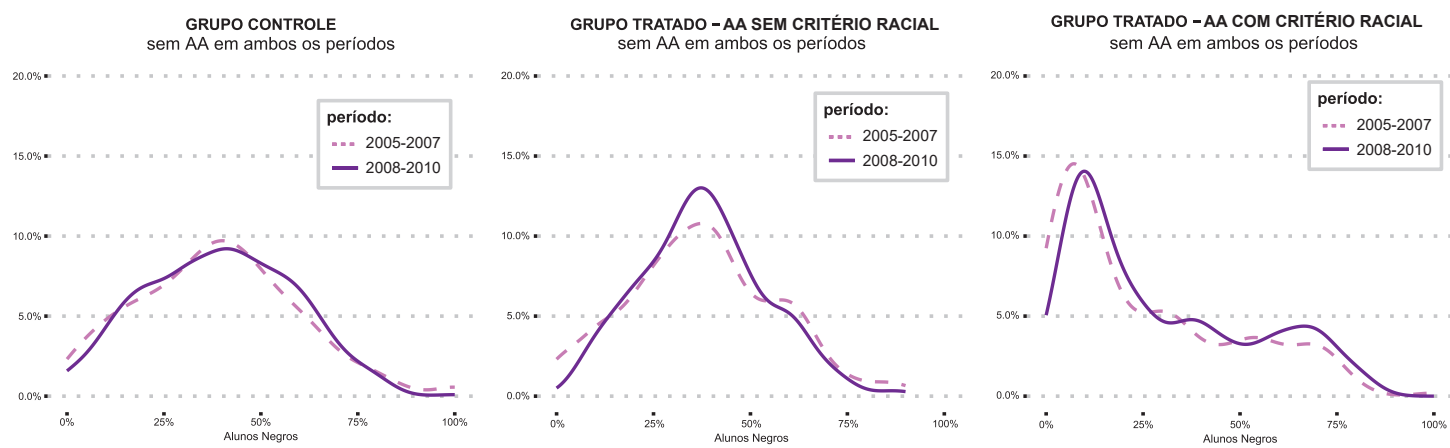

FIGURA 2

\section{DISTRIBUIÇÃO DO TOTAL DE ALUNOS NEGROS POR PERÍODO E POR GRUPO DE TRATAMENTO - BRASIL - 2005-2010}

Fonte: Elaborada pelos autores com base em dados do Enade 2005-2010.

A análise revela que, no período considerado, os programas de AA sem critérios raciais não tiveram êxito em ampliar o acesso dos alunos negros ao ensino superior público federal. Já nas universidades em que programas com critérios raciais foram adotados, houve uma mudança relevante no percentual de alunos negros ingressantes. Tal diferença corrobora a hipótese de que políticas de AA neutras à raça, porém com critérios de seleção socioeconômicos, não necessariamente beneficiam indiretamente os estudantes negros. Em outras palavras, a evidência levantada neste estudo indica que, para que haja maior participação de ingressantes negros nas universidades, é preciso que tais políticas tragam, em algum grau, recortes baseados na raça/cor do candidato.

\section{CONSIDERAÇÕES FINAIS}

Este artigo procurou investigar como a adoção de políticas de AA por universidades federais brasileiras foi acompanhada por alterações no perfil dos ingressantes. Com base em uma comparação de médias ponderadas de características selecionadas do corpo discente entre distintos segmentos, exploramos a heterogeneidade de adoção de políticas de AA para identificar potenciais efeitos destas na matrícula de estudantes de grupos desfavorecidos. Nossos resultados indicam que as políticas de AA adotadas no período considerado foram particularmente eficazes para aumentar a participação de ingressantes dos grupos nominalmente contemplados por elas. Tendo em vista que a maioria das universidades em nossa amostra implantou medidas para favorecer alunos provenientes do ensino médio público e/ou autodeclarados negros, foram estas as subpopulações que mais observaram incrementos na matrícula de ingressantes, em especial nos cursos mais competitivos. 
É importante ressaltar que o aumento na matrícula de negros foi constatado tão somente em universidades que adotaram programas de AA com critérios raciais explícitos, ao contrário do que usualmente se apregoa, no debate das ações afirmativas, de que políticas indiferentes à raça seriam preferidas em razão da associação entre raça e classe. Mostramos que os programas de AA sem critério racial foram acompanhados por um acréscimo insignificante no ingresso de negros. Ao mesmo tempo, universidades com políticas de recorte racial explícito não só testemunharam uma parcela maior de estudantes negros entre os admitidos, como também intensificaram a presença de indivíduos oriundos de camadas populares.

Reconhecemos que a principal restrição deste estudo está relacionada à fonte das informações que usamos para identificar as características dos estudantes em cada curso. Os dados sociodemográficos do questionário do Enade são limitados porque, além de autodeclarados, os cursos são avaliados uma vez a cada três anos. Não obstante, trata-se de uma fonte de informação sobre o conjunto de estudantes matriculados nas universidades federais no período analisado ainda pouco explorada em pesquisas sobre as políticas de cotas, ao menos em âmbito nacional. O cruzamento dos dados do Enade com outras fontes de informação é uma estratégia interessante para se aprimorar a qualidade e a precisão da análise aqui realizada. Por fim, nossa pesquisa é restrita a um único aspecto relativo à adoção de políticas de AA: a alteração no perfil dos ingressantes. Outras questões sobre os efeitos dessas políticas no contexto brasileiro merecem novas investigações, como as taxas de graduação dos beneficiários, os impactos do novo acesso às universidades sobre os rendimentos do mercado de trabalho e as consequências gerais da política sobre a desigualdade socioeconômica.

\section{REFERÊNCIAS}

ARANHA, A. V.; PENA, C. S.; RIBEIRO, S. H. Programas de inclusão na UFMG: o efeito do bônus e do Reuni nos quatro primeiros anos de vigência - um estudo sobre acesso e permanência. Educação em Revista, Belo Horizonte, v. 28, n. 4, p. 317-345, dez. 2012.

BRASIL. Instituto Nacional de Estudos e Pesquisas Educacionais Anísio Teixeira (Inep). Microdados: Enade [2005-2010]. Brasília, 2018. Disponível em: <http://portal. inep.gov.br/web/guest/microdados >. Acesso em: 12 set. 2019.

BRASIL. Lei $\mathrm{n}^{\circ}$ 12.711, de 29 de agosto de 2012. Dispõe sobre o ingresso nas universidades federais e nas instituições federais de ensino técnico de nível médio e dá outras providências. Diário Oficial da União, Brasília, DF, 30 ago. 2012. Seção 1, p. 1. 
BRASIL. Lei no 13.005, de 25 de junho de 2014. Aprova o Plano Nacional de Educação - PNE e dá outras providências. Diário Oficial da União, Brasília, DF, 26 jun. 2014. Seção 1, p. 1.

CAMPOS, L. A.; FERES JÚNIOR, J.; DAFLON, V. T. O desempenho dos cotistas no Enem: comparando as notas de corte do Sisu. Rio de Janeiro: IESP/UERJ, 2014. (Textos para Discussão GEMAA, n. 4).

CARVALHAES, F.; FERES JÚNIOR, J.; DAFLON, V. T. O impacto da Lei de Cotas nos estados: um estudo preliminar. Rio de Janeiro: IESP/UERJ, 2013. (Textos para Discussão GEMAA, n. 1).

CARVALHO, M. P. Gênero na sala de aula: a questão do desempenho escolar. In: MOREIRA, A. F.; CANDAU, V. M. (Org.). Multiculturalismo: diferenças culturais e práticas pedagógicas. Petrópolis: Vozes, 2008. p. 80-124.

CICALÒ, G. A. What do we know about quotas? Data and considerations about the implementation of the quota system in the State University of Rio de Janeiro (UERJ). Universitas Humanística, Bogotá, n. 65, p. 261-278, Jan./June 2008.

DAFLON, V. T.; FERES JÚNIOR, J.; CAMPOS, L. A. Ações afirmativas raciais no ensino superior público brasileiro: um panorama analítico. Cadernos de Pesquisa, São Paulo, v. 43, n. 148, p. 302-327, 2013.

DARITY, W.; DESHPANDE, A.; WEISSKOPF, T. Who is eligible? Should affirmative action be group- or class-based? American Journal of Economics and Sociology, New York, v. 70, n. 1, p. 238-268, 2011.

ESTEVAN, F.; GALL, T.; MORIN, L. P. Redistribution without distortion: evidence from an affirmative action program at a large Brazilian university. São Paulo: Department of Economics/FEA-USP, 2016. (Working Paper, n. 7).

FRANCIS, A. M.; TANNURI-PIANTO, M. Using Brazil's racial continuum to examine the short-term effects of affirmative action in higher education. The Journal of Human Resources, Madison, v. 47, n. 3, p. 754-784, 2012.

GOMES, A. M.; MORAES, K. N. Educação superior no Brasil contemporâneo: transição para um sistema de massa. Educação \& Sociedade, Campinas, v. 33, n. 118, p. 171-190, 2012.

HOLZER, H. J.; NEUMARK, D. Affirmative action: what do we know? Journal of Policy Analysis and Management, New York, v. 25, n. 2, p. 463-490, 2006. 
KARRUZ, A. Oferta, demanda e nota de corte: experimento natural sobre efeitos da Lei de Cotas no acesso à Universidade Federal de Minas Gerais. DADOS: Revista de Ciências Sociais, Rio de Janeiro, v. 61, n. 2, p. 405-462, 2018.

LOPES, A. D. Affirmative action in Brazil: how students' field of study choice reproduces social inequalities. Studies in Higher Education, Abington, v. 42, n. 12, p. 1-17, 2016.

MELLO, U. Affirmative action, centralized admissions and inequality in access to higher education: evidence from Brazil. Madrid: Department of Economics, 2018. Job Market Paper.

NEVES, C. E. B.; MARTINS, C. B. Ensino superior no Brasil: uma visão abrangente. In: DWYER, T. et al. (Org.). Jovens universitários em um mundo em transformação: uma pesquisa sino-brasileira. Brasília: Ipea; Pequim: SSAP, 2016. p. 95-124.

OSORIO, R. G. Classe, raça e acesso ao ensino superior no Brasil. Cadernos de Pesquisa, São Paulo, v. 39, n. 138, p. 867-880, 2009.

SENKEVICS, A. S.; MELLO, U. M. O perfil discente das universidades federais mudou pós-Lei de Cotas? Cadernos de Pesquisa, São Paulo, v. 49, n. 172, p. 184-208, 2019.

UNITED NATIONS EDUCATIONAL, SCIENTIFIC AND CULTURAL ORGANIZATION (UNESCO). World atlas of gender equality in education. Paris: Unesco, 2012.

VILELA, L. et al. As cotas nas universidades públicas brasileiras diminuem a qualidade dos ingressantes? Estudos em Avaliação Educacional, São Paulo, v. 28, n. 69, p. 652-684, 2017.

VIEIRA, R. S.; ARENDS-KUENNING, M. Affirmative action in Brazilian universities: effects on the enrollment of targeted groups. Economics of Education Review, [Oxford], v. 73, Dec. 2019. 


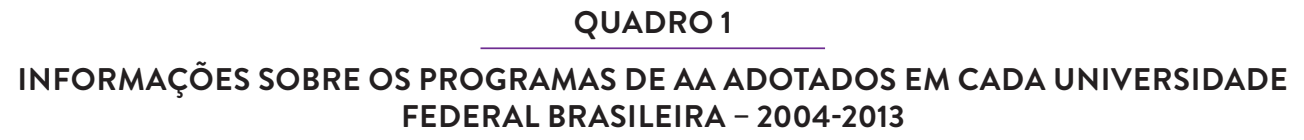

QUADRO 1 INFORMAÇÕES SOBRE OS PROGRAMAS DE AA ADOTADOS EM CADA UNIVERSIDADE
FEDERAL BRASILEIRA - 2004-2013

\begin{tabular}{|c|c|c|c|c|}
\hline IES & $\begin{array}{c}\text { Tipo } \\
\text { de AA }\end{array}$ & Público-Alvo & $\begin{array}{l}\text { Ano de } \\
\text { Adoção }\end{array}$ & Detalhes \\
\hline UFABC & cota & $\begin{array}{l}\text { EMP; negros e } \\
\text { indígenas no } \\
\text { EMP }\end{array}$ & 2007 & $\begin{array}{l}\text { Reserva de } 50 \% \text { das vagas para alunos do } \\
\text { EMP. Dessas vagas, } 27,2 \% \text { ( } 13,6 \% \text { do total) } \\
\text { foram reservadas para negros do EMP e } 0,4 \% \\
(0,2 \% \text { do total) para indígenas no EMP. }\end{array}$ \\
\hline Ufac & - & & 2013 & Sem AA até a Lei de Cotas de 2012. \\
\hline Ufal & cota & $\begin{array}{l}\text { Negros no } \\
\text { EMP; mulheres } \\
\text { negras no EMP }\end{array}$ & 2005 & $\begin{array}{l}\text { Reserva de } 20 \% \text { das vagas para negros. Em } \\
2006,60 \% \text { da cota passou a ser reservada } \\
\text { para mulheres negras. }\end{array}$ \\
\hline Ufam & - & & 2013 & Sem AA até a Lei de Cotas de 2012. \\
\hline UFBA & cota & $\begin{array}{l}\text { EMP; negros e } \\
\text { indígenas no } \\
\text { EMP }\end{array}$ & 2005 & $\begin{array}{l}\text { Reserva de } 36,55 \% \text { das vagas para negros do } \\
\text { EMP, } 2 \% \text { reservadas para indígenas do EMP } \\
\text { e } 6,45 \% \text { das vagas reservadas para alunos do } \\
\text { EMP de todas as raças/cores. }\end{array}$ \\
\hline UFC & - & & 2013 & Sem AA até a Lei de Cotas de 2012. \\
\hline UFCG & - & & 2013 & Sem AA até a Lei de Cotas de 2012. \\
\hline Ufes & cota & EMP & 2008 & $\begin{array}{l}\text { Reserva de } 40 \text { a } 50 \% \text { para alunos do EMP } \\
\text { que estudaram ao menos quatro anos do } \\
\text { ensino fundamental em escolas públicas. }\end{array}$ \\
\hline UFF & bônus & EMP & 2008 & $\begin{array}{l}\text { Bônus de } 10 \% \text { na nota do vestibular para } \\
\text { alunos do EMP. O bônus passou para } 20 \% \\
\text { em } 2012 \text {. }\end{array}$ \\
\hline UFG & cota & $\begin{array}{l}\text { EMP; negros no } \\
\text { EMP }\end{array}$ & 2005 & $\begin{array}{l}\text { Reserva de } 10 \% \text { das vagas para alunos do } \\
\text { EMP e } 10 \% \text { para alunos negros do EMP. Uma } \\
\text { vaga adicional para indígenas. }\end{array}$ \\
\hline UFJF & cota & $\begin{array}{l}\text { EMP; negros no } \\
\text { EMP }\end{array}$ & 2006 & $\begin{array}{l}\text { Reserva de } 50 \% \text { das vagas para alunos do } \\
\text { EMP. Metade da cota era restrita para alunos } \\
\text { negros do EMP. }\end{array}$ \\
\hline Ufla & - & & 2013 & Sem AA até a Lei de Cotas de 2012. \\
\hline UFMA & cota & $\begin{array}{l}\text { EMP; negros; } \\
\text { negros no EMP }\end{array}$ & 2007 & $\begin{array}{l}\text { Reserva de } 25 \% \text { das vagas para alunos do } \\
\text { EMP e } 25 \% \text { para alunos negros. Em } 2010 \text {, as } \\
\text { vagas reservadas aos negros passaram a ser } \\
\text { restritas para alunos negros do EMP. }\end{array}$ \\
\hline UFMG & bônus & $\begin{array}{l}\text { EMP; negros no } \\
\text { EMP }\end{array}$ & 2009 & $\begin{array}{l}\text { Bônus de } 10 \% \text { na nota do vestibular para } \\
\text { alunos do EMP que estudaram ao menos } \\
\text { quatro anos do ensino fundamental em } \\
\text { escolas públicas. Alunos negros que } \\
\text { satisfizessem os mesmos critérios receberiam } \\
\text { um bônus adicional de } 5 \% \text { na nota. }\end{array}$ \\
\hline UFMS & - & & 2013 & Sem AA até a Lei de Cotas de 2012. \\
\hline
\end{tabular}




\section{QUADRO 1}

\section{INFORMAÇÕES SOBRE OS PROGRAMAS DE AA ADOTADOS EM CADA UNIVERSIDADE FEDERAL BRASILEIRA - 2004-2013}

(continuação)

\begin{tabular}{|c|c|c|c|c|}
\hline IES & $\begin{array}{c}\text { Tipo } \\
\text { de AA }\end{array}$ & Público-Alvo & $\begin{array}{l}\text { Ano de } \\
\text { Adoção }\end{array}$ & Detalhes \\
\hline UFMT & cota & $\begin{array}{l}\text { EMP; negros no } \\
\text { EMP }\end{array}$ & 2012 & $\begin{array}{l}\text { Reserva de } 20 \% \text { das vagas para alunos negros } \\
\text { do EMP e } 30 \% \text { para os demais alunos do } \\
\text { EMP. Em ambos os casos, os alunos deveriam } \\
\text { ter concluído todo o ensino fundamental em } \\
\text { escolas públicas. }\end{array}$ \\
\hline Ufop & cota & EMP & 2009 & $\begin{array}{l}\text { Reserva de } 30 \% \text { das vagas para alunos do } \\
\text { EMP. }\end{array}$ \\
\hline UFPA & cota & $\begin{array}{l}\text { EMP; negros no } \\
\text { EMP }\end{array}$ & 2006 & $\begin{array}{l}\text { Reserva de } 20 \% \text { das vagas para alunos negros } \\
\text { do EMP e } 30 \% \text { para alunos do EMP de todas } \\
\text { as raças/cores. }\end{array}$ \\
\hline UFPB & cota & $\begin{array}{l}\text { EMP; negros, } \\
\text { indígenas e } \\
\text { pessoas com } \\
\text { deficiência no } \\
\text { EMP }\end{array}$ & 2011 & $\begin{array}{l}\text { Reserva de } 25 \% \text { das vagas para alunos EMP. } \\
\text { Parte da cota era destinada exclusivamente a } \\
\text { alunos negros e indígenas. Em 2012, o total } \\
\text { de vagas reservadas aumentou para } 30 \% \text {. }\end{array}$ \\
\hline UFPE & bônus & EMP & 2006 & $\begin{array}{l}\text { Bônus de } 10 \% \text { na nota do vestibular para } \\
\text { alunos de EMP próximos aos campi da } \\
\text { universidade. }\end{array}$ \\
\hline UFPEL & - & & 2013 & Sem AA até a Lei de Cotas de 2012. \\
\hline UFPI & cota & EMP & 2007 & $\begin{array}{l}\text { Reserva de } 5 \% \text { das vagas para alunos do EMP } \\
\text { que completaram todo o ensino fundamental } \\
\text { em escolas públicas. Em } 2008 \text {, a reserva de } \\
\text { vagas aumentou para } 20 \% \text {. }\end{array}$ \\
\hline UFPR & cota & EMP; negros & 2005 & $\begin{array}{l}\text { Reserva de } 20 \% \text { das vagas para alunos } \\
\text { do EMP que completaram todo o ensino } \\
\text { fundamental em escolas públicas. } \\
\text { Adicionalmente, reserva de } 20 \% \text { das vagas } \\
\text { para alunos negros. }\end{array}$ \\
\hline UFRB & cota & $\begin{array}{l}\text { EMP; negros e } \\
\text { indígenas no } \\
\text { EMP }\end{array}$ & 2006 & $\begin{array}{l}\text { Reserva de } 36,55 \% \text { das vagas para alunos } \\
\text { negros do EMP, } 2 \% \text { para indígenas do EMP e } \\
6,45 \% \text { para alunos do EMP de todas as raças/ } \\
\text { cores. }\end{array}$ \\
\hline UFRGS & cota & $\begin{array}{l}\text { EMP; negros no } \\
\text { EMP }\end{array}$ & 2008 & $\begin{array}{l}\text { Reserva de } 15 \% \text { das vagas para alunos } \\
\text { negros do EMP que concluíram o ensino } \\
\text { fundamental em escolas públicas. Metade } \\
\text { da cota ( } 15 \% \text { do total) era reservada a alunos } \\
\text { negros do EMP. }\end{array}$ \\
\hline UFRJ & cota & EMP & 2011 & $\begin{array}{l}\text { Reserva de } 20 \% \text { das vagas para alunos do } \\
\text { EMP do RJ. }\end{array}$ \\
\hline UFRN & bônus & EMP & 2006 & $\begin{array}{l}\text { Bônus na nota do vestibular para alunos do } \\
\text { EMP do RN. O valor do bônus era diferente } \\
\text { para cada curso. }\end{array}$ \\
\hline UFRPE & bônus & EMP & 2005 & $\begin{array}{l}\text { Bônus de } 10 \% \text { na nota do vestibular para } \\
\text { alunos do EMP de escolas do interior de PE. }\end{array}$ \\
\hline
\end{tabular}


QUADRO 1

\section{INFORMAÇÕES SOBRE OS PROGRAMAS DE AA ADOTADOS EM CADA UNIVERSIDADE FEDERAL BRASILEIRA - 2004-2013}

\begin{tabular}{|c|c|c|c|c|}
\hline IES & $\begin{array}{l}\text { Tipo } \\
\text { de AA }\end{array}$ & Público-Alvo & $\begin{array}{l}\text { Ano de } \\
\text { Adoção }\end{array}$ & Detalhes \\
\hline UFRR & - & & 2013 & Sem AA até a Lei de Cotas de 2012. \\
\hline UFRRJ & bônus & EMP & 2010 & $\begin{array}{l}\text { Bônus de } 10 \% \text { na nota do vestibular para } \\
\text { alunos do EMP. }\end{array}$ \\
\hline UFS & cota & $\begin{array}{l}\text { EMP; negros e } \\
\text { indígenas no } \\
\text { EMP }\end{array}$ & 2010 & $\begin{array}{l}\text { Reserva de } 50 \% \text { das vagas para alunos do } \\
\text { EMP que estudaram ao menos quatro anos } \\
\text { do ensino fundamental em escolas públicas. } \\
\text { Era restrita a alunos negros e indígenas do } \\
\text { EMP } 70 \% \text { dessa cota. }\end{array}$ \\
\hline UFSC & cota & $\begin{array}{l}\text { EMP; negros no } \\
\text { EMP }\end{array}$ & 2008 & $\begin{array}{l}\text { Reserva de } 20 \% \text { das vagas para alunos } \\
\text { do EMP. Adicionalmente, } 10 \% \text { de vagas } \\
\text { reservadas para alunos negros do EMP. }\end{array}$ \\
\hline UFSCar & cota & $\begin{array}{l}\text { EMP; negros no } \\
\text { EMP }\end{array}$ & 2008 & $\begin{array}{l}\text { Reserva de } 20 \% \text { das vagas para alunos do } \\
\text { EMP. Era restrita para alunos negros do EMP } \\
35 \% \text { dessa cota. Em 2011, a cota passou para } \\
40 \% \text { do total de vagas. }\end{array}$ \\
\hline UFSJ & cota & $\begin{array}{l}\text { EMP; negros e } \\
\text { indígenas no } \\
\text { EMP }\end{array}$ & 2010 & $\begin{array}{l}\text { Reserva de } 50 \% \text { das vagas para alunos } \\
\text { do EMP que completaram todo o ensino } \\
\text { fundamental em escolas públicas. Era } \\
\text { restrita a alunos negros e indígenas do EMP } \\
46 \% \text { da cota ( } 23 \% \text { das vagas totais). }\end{array}$ \\
\hline UFSM & cota & $\begin{array}{l}\text { EMP; negros; } \\
\text { indígenas; } \\
\text { pessoas com } \\
\text { deficiência }\end{array}$ & 2008 & $\begin{array}{l}\text { Reserva de } 11 \% \text { das vagas para alunos } \\
\text { negros, } 5 \% \text { para deficientes, } 20 \% \text { para } \\
\text { alunos do EMP que concluíram todo o } \\
\text { ensino fundamental em escolas públicas e } \\
\text { oito novas vagas para indígenas. Até } 2012 \text {, } \\
\text { a reserva para negros aumentou um ponto } \\
\text { percentual a cada ano. }\end{array}$ \\
\hline UFT & cota & Indígenas & 2005 & Reserva de $5 \%$ das vagas para indígenas. \\
\hline UFTM & bônus & EMP & 2009 & $\begin{array}{l}\text { Bônus de } 10 \% \text { na nota do vestibular para } \\
\text { alunos do EMP que estudaram quatro anos } \\
\text { do ensino fundamental em escolas públicas. }\end{array}$ \\
\hline UFU & cota & EMP & 2011 & $\begin{array}{l}\text { Um exame vestibular especial foi criado para } \\
\text { alunos do EMP que estudaram ao menos } \\
\text { quatro anos do ensino fundamental em } \\
\text { escolas públicas. As vagas reservadas para } \\
\text { esse vestibular variavam de entre } 25 \% \text { a } 50 \% \\
\text { do total. }\end{array}$ \\
\hline UFV & - & & 2013 & Sem AA até a Lei de Cotas de 2012. \\
\hline UnB & cota & Negros & 2004 & $\begin{array}{l}\text { Reserva de } 20 \% \text { das vagas para alunos } \\
\text { negros. }\end{array}$ \\
\hline Unifal & - & & 2013 & Sem AA até a Lei de Cotas de 2012. \\
\hline Unifap & - & & 2013 & Sem AA até a Lei de Cotas de 2012. \\
\hline Unifei & - & & 2013 & Sem AA até a Lei de Cotas de 2012. \\
\hline
\end{tabular}




\section{QUADRO 1}

\section{INFORMAÇÕES SOBRE OS PROGRAMAS DE AA ADOTADOS EM CADA UNIVERSIDADE FEDERAL BRASILEIRA - 2004-2013}

\begin{tabular}{|c|c|c|c|c|}
\hline IES & $\begin{array}{l}\text { Tipo } \\
\text { de AA }\end{array}$ & Público-Alvo & $\begin{array}{l}\text { Ano de } \\
\text { Adoção }\end{array}$ & Detalhes \\
\hline Unifesp & cota & $\begin{array}{l}\text { Negros e } \\
\text { indígenas no } \\
\text { EMP }\end{array}$ & 2005 & $\begin{array}{l}\text { Reserva de } 10 \% \text { das vagas para alunos negros } \\
\text { e indígenas. }\end{array}$ \\
\hline Unir & - & & 2013 & Sem AA até a Lei de Cotas de 2012. \\
\hline Unirio & - & & 2013 & Sem AA até a Lei de Cotas de 2012. \\
\hline Univasf & cota & EMP & 2010 & $\begin{array}{l}\text { Reserva de } 50 \% \text { das vagas para alunos do } \\
\text { EMP. }\end{array}$ \\
\hline $\begin{array}{l}\text { URG } \\
\text { (FURG) }\end{array}$ & bônus & $\begin{array}{l}\text { EMP; negros no } \\
\text { EMP }\end{array}$ & 2010 & $\begin{array}{l}\text { Bônus de } 6 \% \text { na nota do vestibular para } \\
\text { alunos do EMP e um bônus adicional de } \\
3 \% \text { para alunos negros do EMP. Em } 2011 \text {, } \\
\text { os valores do bônus foram alterados para, } \\
\text { respectivamente, } 4 \% \text { (EMP) e } 6 \% \text { (negros no } \\
\text { EMP). }\end{array}$ \\
\hline UTFPR & cota & EMP & 2008 & $\begin{array}{l}\text { Reserva de } 50 \% \text { das vagas para alunos } \\
\text { do EMP que concluíram todo o ensino } \\
\text { fundamental em escolas públicas. }\end{array}$ \\
\hline
\end{tabular}

Fonte: Vieira e Arends-Kuenning (2019) com base nos editais de admissão das universidades.

Nota: EMP refere-se aos alunos que estudaram todos os anos do ensino médio na rede pública. O termo negro é usado para se referir tanto às AA voltadas para o conjunto de pretos e pardos quanto às AA que definiam negros como o público-alvo das políticas. 